\title{
A FISTULA FOR THE COLLECTION OF EPIDIDYMAL SEMEN FROM THE BULL
}

\author{
J. P. BENNETT AND L. E. A. ROWSON \\ A.R.C. Unit of Reproductive Physiology and Biochemistry, \\ University of Cambridge*
}

(Received 20th December 1962)

\begin{abstract}
Summary. A technique of cannulation of the epididymis of the bull with the subsequent establishment of a patent fistula is described, which allows for the repeated collection of epididymal spermatozoa and secretions from the living animal.
\end{abstract}

Before 1959, studies on epididymal spermatozoa and secretions were made with slaughterhouse material (Czarnetzky \& Henle, 1938; Lasley \& Bogart, 1944a, b; Lasley \& Mayer, 1944; Bialy \& Smith, 1959). Semen was expressed through a slit made into a tubule of the epididymis, by pressure exerted from the contents of a syringe introduced into the cut end of the vas deferens. This method of obtaining epididymal semen has several disadvantages. The donor animal is killed and only the one sample can, therefore, be obtained. There is often a delay between the time of slaughter and the collection of the semen, and the collection procedure is not always successful.

A method for the collection of ram epididymal semen from the living animal was developed by White, Larson \& Wales (1959), which overcame the abovementioned difficulties.

An attempt has been made in our laboratory to use a similar method of collecting epididymal bull semen for biochemical studies on the proteins of epididymal secretion and certain investigations into the physiological behaviour of epididymal spermatozoa following cold shock. Cannulation of the vas deferens in the region of the posterior dorsal part of the scrotum of a 2-year-old bull was carried out to establish a fistula. This site was considered the most favourable for collection of epididymal semen.

The cannula was of simple design (Text-fig. 1). A polythene tube (diameter $1.0 \mathrm{~mm}$, bore $0.5 \mathrm{~mm}$ ) was passed through the centre of a circular, pliable collar of sheet polythene (thickness $1.0 \mathrm{~mm}$, radius $3.0 \mathrm{~cm}$ ). One end of the polythene tube was trimmed to a blunt point to assist insertion into the vas deferens. The collar was held in position by two restricting rubber washers fixed to the polythene tube with an epoxy resin adhesive (Araldite-Aero Research Ltd).

Under general anaesthesia (Nembutal followed by Cyclopropane) with the animal dorsally recumbent and the rear legs abducted, a small incision was made immediately over the spermatic cord in the posterior part of the

* Postal address: Animal Research Station, 307 Huntingdon Road, Cambridge. 
scrotum. By blunt dissection, the spermatic cord was isolated, and by rolling between finger and thumb the vas deferens was identified as a hard, cord-like structure. The tunica was incised to allow a centimetre or two of the vas deferens to be withdrawn. A $2 \cdot 0 \mathrm{~mm}$ incision was then made into the vas deferens itself and the polythene cannula was inserted to a length of 8 to $10 \mathrm{~cm}$ towards the epididymis. A silk ligature (Text-fig. 2, A) (Arabrasilk, 00, Armour Laboratories) was placed around the cannulated vas deferens and loosely tied. A ligature (Text-fig. 2, B) was next tied around the uncannulated part of the vas deferens, posteriorly, and tightened, leaving a free length of silk. The vas

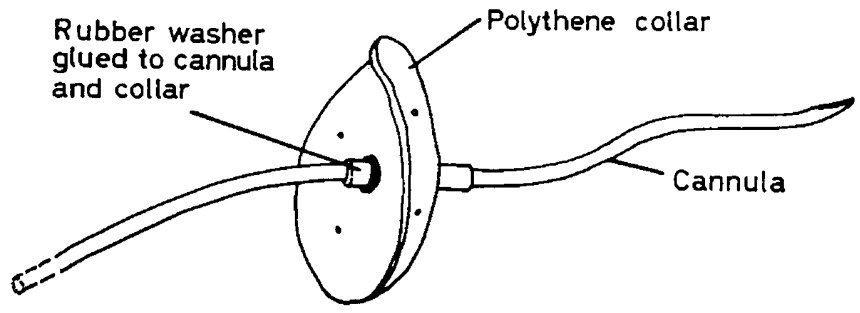

Text-fig. 1. The polythene cannula. Polythene collar: thickness $1.0 \mathrm{~mm}$, radius $3.0 \mathrm{~cm}$. Cannula: polythene tube, diameter $1.0 \mathrm{~mm}$, bore $0.5 \mathrm{~mm}$.

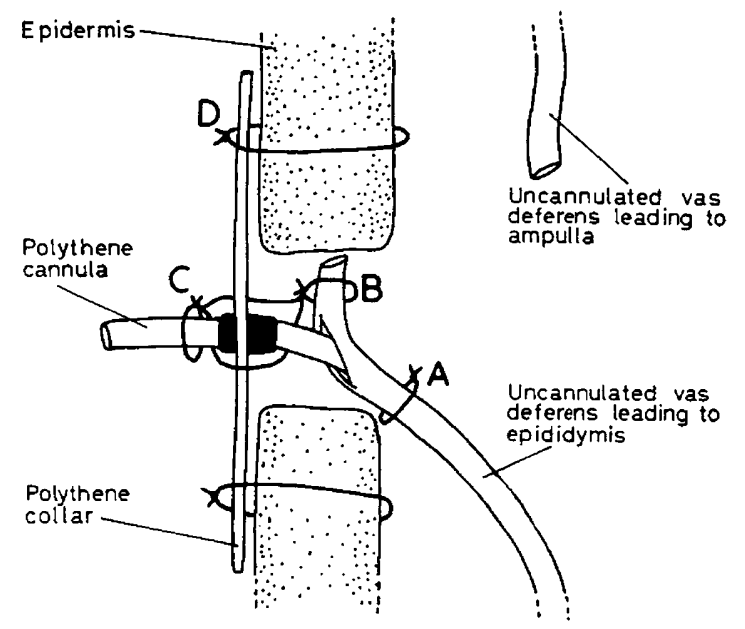

TexT-FIG. 2. Cannulation of the bull epididymis. A, B, C, D = Silk ligatures labelled alphabetically in order of tying.

deferens was severed transversely $1.0 \mathrm{~mm}$ above this ligature. The free end of silk (Text-fig. 2, C) was brought upwards through the polythene collar, around the polythene tube and down through the collar into the wound, to be secured to the vas deferens, which was drawn up so that the cannulated part was situated just below the skin of the scrotum. The wound was then closed around the vas deferens and the polythene collar secured to the epidermis with silk sutures (Text-fig. 2, D). Penicillin (Glaxo Laboratories Ltd) was dusted into the wound prior to closure to prevent infection.

Upon removal of the cannula 2 to 3 weeks after surgery a healthy fistula 


\section{PLATE 1}

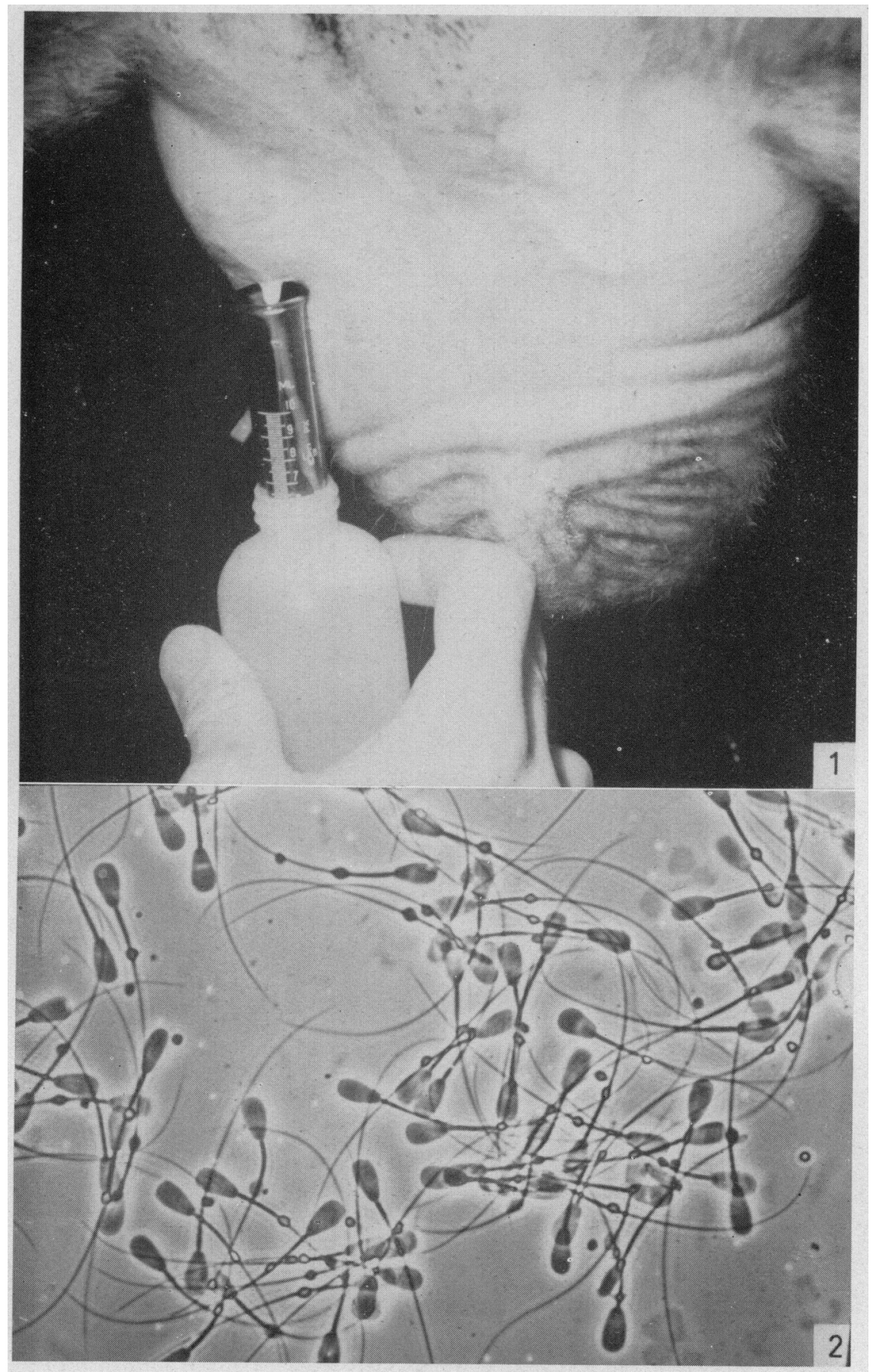

FIG. 1. Collection of epididymal semen from the fistula by electro-ejaculation.

FIG. 2. Bull cpididymal spermatozoa collected through the fistula. $\times 640$.

(Facing p. 62) 
was established. Complete patency was not obtained until some 3 months after the operation, there being an initial, apparent closing of the wound. The fistula has been patent 19 months to date and would appear to be permanent.

Regular collections of epididymal semen are made from the fistula by electroejaculation into a glass measuring tube (Pl. 1, Fig. 1) surrounded by an insulated warm water jacket $\left(20^{\circ} \mathrm{C}\right)$ to guard against cold shock. A total of 0.3 to $0.6 \mathrm{ml}$ of secretion can readily be obtained from the fistula with minimal loss at collection. A very slow emission of epididymal secretion occurs from the fistula during the periods between collections. Ejaculations from the penis are collected through a large funnel into a polythene bottle placed beneath the prepuce. In the animal described it was possible to collect sperm-free secretions from the penis since the vas deferens on the other side was ligated. These secretions are being used in the physiological tests on epididymal spermatozoa collected via the fistula.

The spermatozoa obtained in this manner from the epididymis characteristically show the presence of kinoplasmic droplets attached to the sperm tail (Pl. I, Fig. 2). The mean sperm density of five different samples of epididymal semen recovered from the bull fistula was $7632.0 \times 10^{6}$ (s.D. 136.2) $/ \mathrm{ml} / \mathrm{emission}$ measured on a calibrated absorptiometer. The spermatozoa were always slowly motile on collection, becoming more active on the microscope warm stage at $37^{\circ} \mathrm{C}$. In the presence of substrate (Krebs' Ringer bicarbonate solution, minus calcium, plus fructose) the sperm movement became extremely vigorous.

Sperm counts of five different semen samples on nigrosin-eosin smears (Campbell, Dott \& Glover, 1956) showed only 10\% dead spermatozoa (s.D. 2.32). Bishop, Campbell, Hancock \& Walton (1954) have reported a mean of $22.1 \%$ dead spermatozoa in 122 samples of ejaculated bull semen, and Campbell, Hancock \& Shaw (1960) found an average of $21 \%$ dead spermatozoa. If this bull produced average semen, it would, therefore, seem that 11 to $12 \%$ of spermatozoa leaving the epididymis die on the way down the efferent tracts to the penis. This accords closely with Lasley \& Bogart (1944a) who found in the boar $91 \%$ live spermatozoa in epididymal semen and $75.7 \%$ live spermatozoa in ejaculated semen.

The use of epididymal secretions recovered from the living animal in the manner described, should provide much valuable material for studies leading to an understanding of the behaviour and storage of spermatozoa in the epididymis and the effects of accessory secretions upon epididymal spermatozoa.

\section{REFERENCES}

Bialy, A. \& Smith, V. R. (1959) Cold shock of epididymal spermatozoa. F. Dairy Sci. 42, 2002.

Bishop, M. W., Campbell, R. C., Hancock, J. L. \& Walton, A. (1954) Semen characteristics in the bull. F. agric. Sci. 44, 227.

Campeell, R. C., Dott, H. M. \& Glover, T. D. (1956) Nigrosin eosin as a stain for differentiating live and dead spermatozoa. F. agric. Sci. 48, I.

Campbele, R. G., Hancock, J. L. \& Shaw, I. G. (1960) Cytological characteristics and fertilising capacity of bull spermatozoa. 7. agric. Sci. 55, 91.

Czarnetzky, E. J. \& HEnle, W. (1938) A pressure device for the separation of mammalian spermatozoa from the isolated epididymis. Proc. Soc. exp. Biol., N.Y. 38, 63.

LAsley, J. F. \& Bogart, R. (1944a) A comparative study of epididymal and ejaculated spermatozoa of the boar. F. Anim. Sci. 3, 360. 
LASLEY, J. F. \& BogART, R. (1944b) Some factors affecting the resistance of ejaculated and epididymal spermatozoa of the boar to different environmental conditions. Amer. F. Physiol. 141, 619.

LASLEY, J. F. \& MAYER, D. T. (1944) A variable physiological factor necessary for the survival of bull spermatozoa. 7. Anim. Sci. 3, 129.

White, I. G., LARson, L. H. \& Wales, R. G. (1959) Method for the in vivo collection of epididymal spermatozoa and for their comparison with ejaculated cells. Fertil. Steril. 10, 571. 